How to cite: Niţoaia, A., Maier, N., Kocis, I. (2021) Analysis of Estimated Doppler Radar Rainfalls. Case Studies for North-Western Romania Using Two Wsr-98d Doppler Radars. 2021 "Air and Water - Components of the Environment" Conference Proceedings, Cluj-Napoca, Romania, p. 209-224, DOI: 10.24193/AWC2021_20.

\title{
ANALYSIS OF ESTIMATED DOPPLER RADAR RAINFALLS. CASE STUDIES FOR NORTH-WESTERN ROMANIA USING TWO WSR-98D DOPPLER RADARS
}

\author{
Andrei NIT⿱宀OAIA ${ }^{1}$, Narcis MAIER ${ }^{1}$, István KOCIS ${ }^{2}$ \\ DOI: 10.24193/AWC2021_20
}

\begin{abstract}
This paper aims to analyse the precipitation quantities measured during August, 2020 at the meteorological stations and gauging stations in north-western Romania, compared to the WSR-98D Doppler weather radar estimations. This study was motivated by the presence of major differences in the precipitations field between both radar estimations and gauging stations measurements, and this paper aims to identify the factors that led to these differences. The results showed that during convective and pre-frontal situations, the WSR-98D Oradea (RDOD) and WSR-98D Bobohalma (RDBB) weather radars detected the water amounts and their maximum quantities. Hence, RDOD detects precipitation with a higher accuracy for the Apuseni Mountains and the western part of Cluj and Sălaj counties, while RDBB detects the amounts of precipitations for about the entire area. During frontal situations, when the frontal systems occur early in the morning, the estimations are less accurate, but once more, RDBB detects the area with important rainfall amounts, yet underestimated.
\end{abstract}

Keywords: north-western Romania, Doppler weather radar, precipitations.

\section{INTRODUCTION}

The rainfall forecast is one of the most difficult, but also the most important activity for meteorology and hydrology. Estimating rainfalls using the weather radars and the gauge stations represents different measurement methods.

Rain gauges are traditionally used to measure the amount of rainfall at a given location, while weather radars detects rainfalls for an entire area, usually within a radius of $250 \mathrm{~km}$.

Espinosa et al. (2015) analyzes two heavy rainfall situations using three Doppler radars, in order to identify the accuracy, according to the distance and topographic influence.

Burcea et al. (2012) in their study for the Moldavian Plateau (north-eastern Romania), using one Doppler radar compared the rainfall amounts estimated by

\footnotetext{
${ }^{1}$ National Meteorological Administration - Northern Transylvania Regional Meteorological Center, Cluj-Napoca, Romania, nitoaia.andrei@gmail.com , narcis.maier@gmail.com

${ }^{2}$ Babeș-Bolyai University, Faculty of Geography, 5-7, Clinicilor Street, Cluj-Napoca, 400006, Cluj

Country, Romania,kfistvan@yahoo.com
} 
weather radar and also recorded within gauge stations. The result was that the best radar accuracy is within a radius of $150 \mathrm{~km}$.

Kreklow et. al. (2020) realized a climatological radar study for Germany, getting results meant to ease the climatic studies of the precipitation, according to the season, orography and rainfall intensity.

Unfortunately for the forecasters, the weather radar is limited, which often represents a difficulty for nowcasting rainfall weather forecast, especially in terms of estimating the quantities.

The study area natural frame is characterized through heterogeneity, being present all the major landforms (mountains, plateaus, hills, plains), the hills and the plateaus being predominant.

\section{DATA AND METHODS}

In this study, a comparative analysis regarding the rainfall amount estimated by RDOD and RDBB weather radars and measured at the gauging stations was made, in north-western Romania, for August, 2020 period.

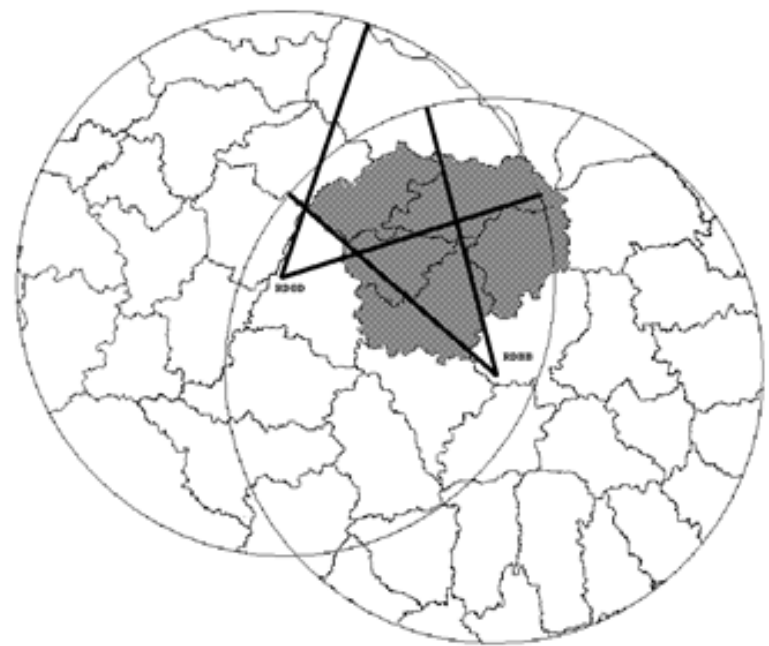

Fig. 1. Northwestern Romania - the study area

The data used in the present study consists of daily rainfall amount maps. The radar data was collected from Doppler Weather Radar database, RDOD, situated in Bihor county and RDBB, situated in Mureș county, the study area being entirely within the scanning radius of the both radars. The USP (User Selectable Precipitation - $24 \mathrm{hrs}$ ) radar product was used.

The USP radar product from both radars were compared with the rainfall amounts measured at the gauging stations from the analyzed area. It is important to mention that during $11^{\text {th }}$ to $20^{\text {th }}$ August 2020, the USP radar product from RDOD was unavailable because of technical issues, so for this interval only the USP radar product from RDBB was used. 
For the case studies identification of the rainy days from the weather stations subordinated to the Northern Transylvania Regional Meteorological Center was performed. The result was 14 cases (days) with precipitations.

Afterwards, a daily synoptic weather conditions associated with air instability was made. For this classification, the http://www.wetter3.de/Archiv/, and http://www.esrl.noaa.gov archives were consulted. For this stage, we consulted distribution field of the geopotential height at $500 \mathrm{hPa}$ level (gpdam) and the distribution of the surface pressure level and associated frontal systems.

For the entire month, the $4^{\text {th }}-5^{\text {th }}, 7^{\text {th }}-8^{\text {th }}, 9^{\text {th }}-11^{\text {th }}, 15^{\text {th }}-16^{\text {th }}, 17^{\text {th }}-19^{\text {th }}, 23^{\text {rd }}-25^{\text {th }}$ of August rainy days cases were identified.

\section{THE ANALYSYS Of THE INSTABILITY SITUATIONS. CASE STUDIES}

\section{1. $4^{\text {th }}-5^{\text {th }}$ of August, 2020}

The weather during $4^{\text {th }}$ to $5^{\text {th }}$ of August, 2020 was influenced by the presence of a Mediterranean depression, centered on the Adriatic Sea, visible on the distribution field of the geopotential height at $500 \mathrm{hPa}$ level and also on the distribution of the surface pressure level and associated frontal systems (Fig.2). For the analysed region, the southern mid-altitude air circulation prevailed, in $4^{\text {th }}$ of August, 2020, in the Cluj and Sălaj counties mountain area, the initiation of some convective systems who migrated north-northwest and brought isolated rainfalls, the maximum amount being $8.8 \mathrm{~mm}$, at Supuru de Jos station.

The images of the RDOD and RDBB quantitative rainfall estimations identify the Apuseni (Cluj County) and Plopiș (Sălaj County) Mountains as convective systems initial spot development, but a difference regarding the quantitative rainfall estimations for the Satu Mare county is obvious. Thus, RDBB estimates quantities up to $25 \mathrm{~mm}$, while RDOD only $6.5 \mathrm{~mm}$ for the area of interest.

The distances between precipitation area and RDBB was approximately $125 \mathrm{~km}$, while RDOD was just $70 \mathrm{~km}$ far. Thereby, for Supuru de Jos station, RDBB detected a $6.5-12.5 \mathrm{~mm}$ pixel, and RDOD a $2.5-6.5 \mathrm{~mm}$ pixel, so the accuracy is better for RDBB, despite the great distance. Both radars rainfall estimations were similar for the Vlădeasa Mountain area.

On the $5^{\text {th }}$ of August, the atmospheric conditions are changing, with the advance of a "cut-off" low, blocked by the anticyclonic ridge, centered on the area of interest (Fig.3). This "cut-off" low generated the ascending of the air masses, across the OașGutâi-Țibleș mountain range from Satu Mare and Maramureș counties.

In this atmospheric conditions, the convective cells migrated along the mountain range, on a SE-NW direction, generating on the southern slope water amounts up to $29.7 \mathrm{~mm} / 24 \mathrm{hrs}$ (Lăpușel gauging station). RDBB estimated a maximum water amount of around $40 \mathrm{~mm}$, while RDOD only $9-10 \mathrm{~mm} / 24 \mathrm{hrs}$. Both radars are situated within a radius of $150 \mathrm{~km}$. The water amount estimated by RDBB for the Lăpuşel area is almost $35 \mathrm{~mm} / 24 \mathrm{hrs}$. Also, compared to the previous day, because of the dynamic convection, lightning was detected. Again, the quantitative rainfall estimations for the Vlădeasa Mountains are similar for both radars. 


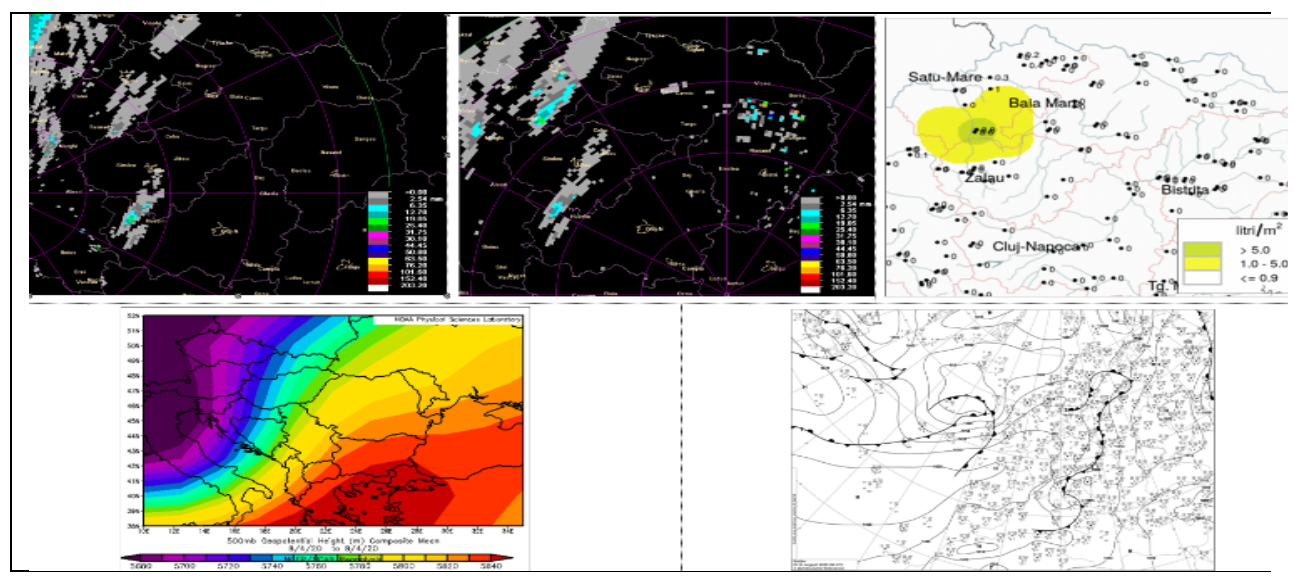

Fig. 2. The USP radar product for RDOD (up-left) and RDBB (up-center), The 24 hrs water amounts recorded at the gauging stations map (up-right), distribution field of the geopotential height at 500 hPa level (gpdam, down-left), sea level pressure and associated frontal systems on the $4^{\text {th }}$ of August, 2020, 06 GMT (down-right). Source: Cluj Weather

Forecast Regional Service Radar Archive (2020), N.M.A. Archive, http://www.wetter3.de/Archiv/, http://www.esrl.noaa.gov
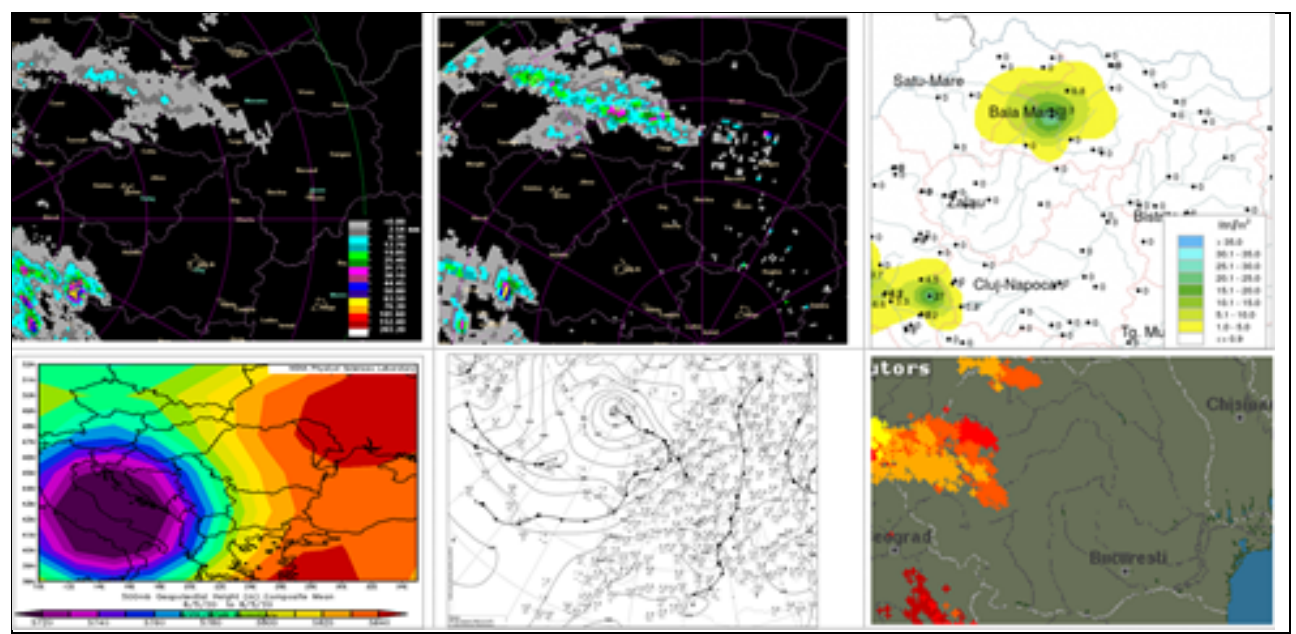

Fig. 3. The USP radar product for RDOD (up-left) and RDBB (up-center), the 24 hrs water amounts recorded at the gauging stations map (up-right), distribution field of the geopotential height at 500 hPa level (gpdam, down-left), sea level pressure and associated frontal systems on the $5^{\text {th }}$ of August, 2020, 12 GMT (down-center), the electrical discharges map (down-right). Source: Cluj Weather Forecast Regional Service Radar Archive (2020), N.M.A. Archive, http://www.wetter3.de/Archiv/, http://www.esrl.noaa.gov, https://www.blitzortung.org/en/archive_data.php

\section{2. $7^{\text {th }}-8^{\text {th }}$ of August, 2020}

The synoptic analyses of the $7^{\text {th }}$ to $8^{\text {th }}$ of August, 2020 highlights a Mediterranean depression passing the southern flank of Romania. If the convective activity is very 
intense in the Balkan area, it is opposite in the analysed area (the prove being the missing lightning phenomena, especially on $7^{\text {th }}$ of August). (Fig 4) The estimated water amounts on $7^{\text {th }}$ of August highlights a migration on a east-west direction of the cloud formations, initially developed in Mureș and Târnava (Mureș County) hydrographical basins. Both radars detected the cloud systems and water amounts fallen in Cluj County and afferent mountain area.

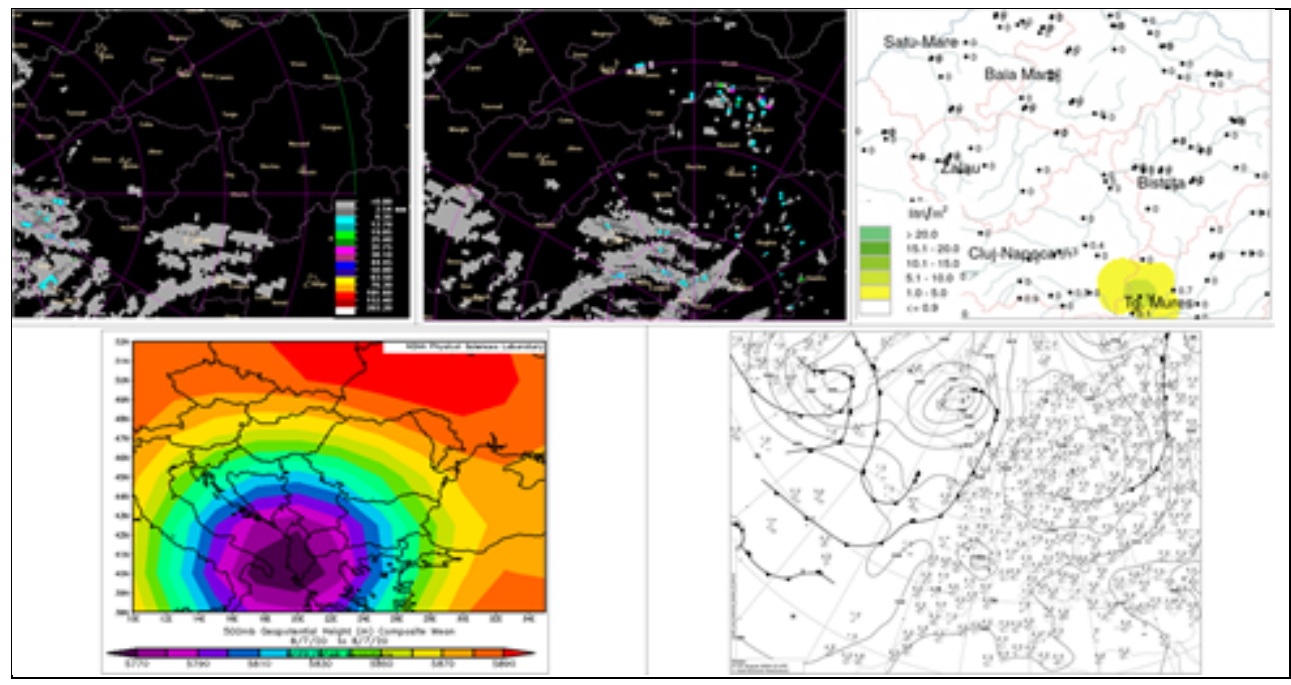

Fig. 4. The USP radar product for RDOD (up-left) and RDBB (up-center), The 24 hrs water amounts recorded at the gauging stations map (up-right), distribution field of the geopotential height at 500 hPa level (gpdam, down-left), sea level pressure and associated frontal systems on the $7^{\text {th }}$ of August, 2020, 12 GMT (down-right). Source: Cluj Weather Forecast Regional Service Radar Archive (2020), N.M.A. Archive, http://www.wetter3.de/Archiv/, http://www.esrl.noaa.gov

On the $8^{\text {th }}$ of August, the low pressure system was positioned on Romania's southern side, and the interest area was at the contact between the depression and the Scandinavian anticyclonic ridge, situated in north-western flank. The electrical discharges (Fig. 5) highlights the intense convective activity.

Thus, the water amounts registered were about $31 \mathrm{~mm} / 24 \mathrm{hrs}$ (at Răzoare gauging station, Maramureș County), located west of Târgu Lăpuș weather station. Despite the significant distance (120 km for RDBB and $150 \mathrm{~km}$ for RDOD), the estimations of both radars were accurate (around 30-32 mm/24 hrs). For Cluj County, even though the distances are different (120 km for RDOD and $70 \mathrm{~km}$ for RDBB), the estimations were quite similar.

\section{3. $9^{\text {th }}-11^{\text {th }}$ of August, 2020}

For the aforementioned period, the distribution field of the geopotential height at $500 \mathrm{hPa}$ level highlights the passage of an upper backward low towards Black Sea, materialized through a north-north-eastern air circulation. On the $9^{\text {th }}$ of August, the cloud formations, initially developed on northern flank of the Eastern Carpathians, moved towards southern zone, generating water amounts below to $15 \mathrm{~mm} / 24 \mathrm{hrs}$ 
(Oaș Depression, Fig. 6). The RDOD and RDBB, situated between 150-200 km distance from the precipitations area, estimated rainfalls for small areas.

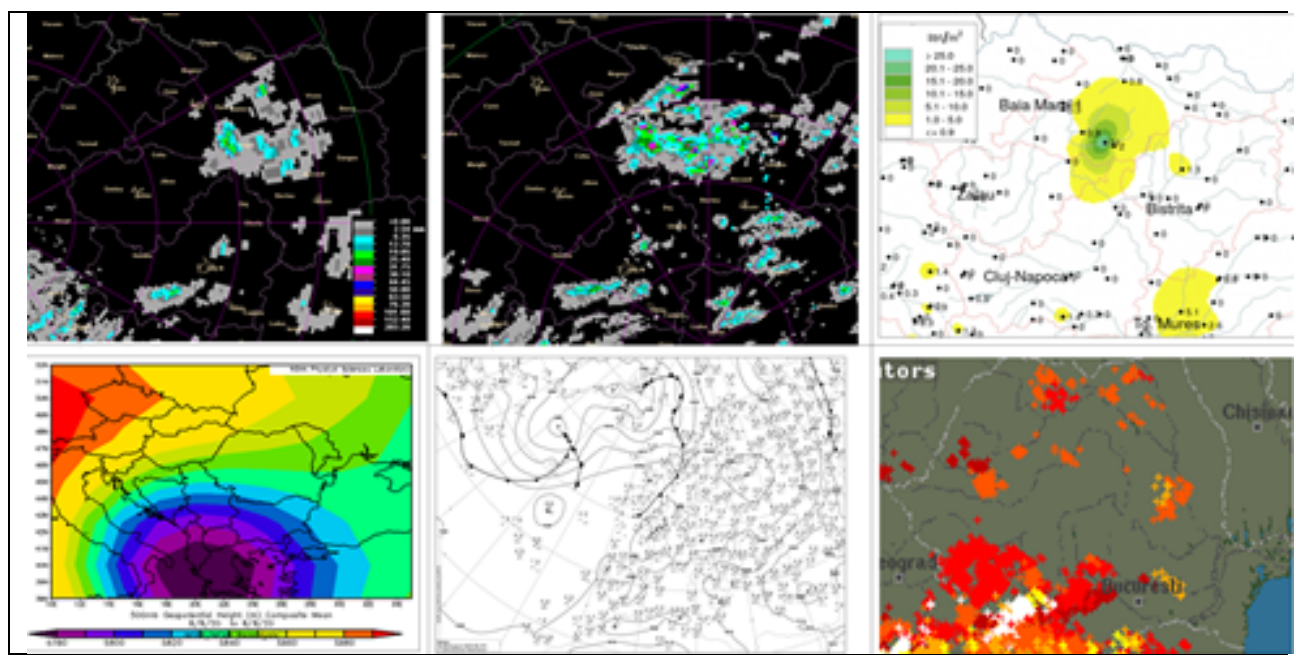

Fig. 5. The USP radar product for RDOD (up-left) and RDBB (up-center), the $24 \mathrm{hrs}$ water amounts recorded at the gauging stations map (up-right), distribution field of the geopotential height at 500 hPa level (gpdam, down-left), sea level pressure and associated frontal systems on the $8^{\text {th }}$ of August, 2020, 12 GMT (down-center), the electrical discharges map (down-right). Source: Cluj Weather Forecast Regional Service Radar Archive (2020), N.M.A. Archive, http://www.wetter3.de/Archiv/, http://www.esrl.noaa.gov, https://www.blitzortung.org/en/archive_data.php

The RDBB weather radar estimates water amounts between 6.5 to $12.5 \mathrm{~mm}$, while RDOD does not estimate the precipitations area located in north-eastern side of Satu Mare County and gives an underestimated water amount for Baia Mare weather station (less than $5 \mathrm{~mm}$, while the water amount recorded was $12.5 \mathrm{~mm}$ ). Also, the north-western part of the Bistriţa-Năsăud county is well estimated by RDBB, situated between 100-150 km distance, and less estimated by RDOD (located to more than $200 \mathrm{~km}$ distance).

On the $10^{\text {th }}$ of August, the convective activity was intensified, especially in the mountain area, where the rainfall amounts exceeded $15 \mathrm{~mm}$, with a maximum of $45.2 \mathrm{~mm}$ in $24 \mathrm{hrs}$ at Firiza gauging station, respectively $34.0 \mathrm{~mm}$ in $24 \mathrm{hrs}$ at Pășunea Mare (Fig. 7). The radar estimations highlight a major difference between RDOD and RDBB radars, especially for Maramureș and Satu Mare counties.

Thereby, RDBB estimated water amounts of approximately $45-50 \mathrm{~mm}$ in $24 \mathrm{hrs}$ in the area of Firiza (MM), and for Satu Mare County (Oaș Depression zone), mean quantities of 35-40 mm. Opposite to RDBB, the RDOD radar underestimated the water amount fallen in the area, with an isolated spot of $25 \mathrm{~mm}$ in $24 \mathrm{hrs}$ (Maramureș County). For Cluj and Sălaj counties western part, both radars have a good correlation within precipitations area. 

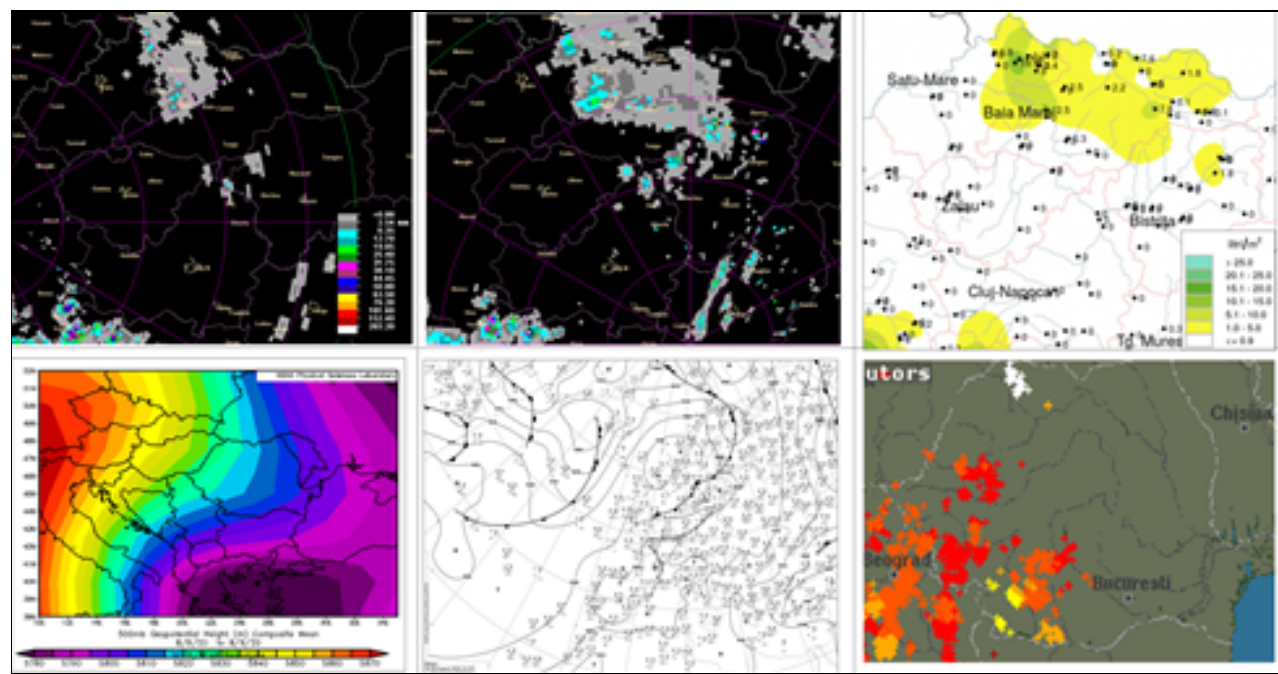

Fig. 6. The USP radar product for RDOD (up-left) and RDBB (up-center), the 24 hrs water amounts recorded at the gauging stations map (up-right), distribution field of the geopotential height at 500 hPa level (gpdam, down-left), sea level pressure and associated frontal systems on the $9^{\text {th }}$ of August, 2020, 12 GMT (down-center), the electrical discharges map (down-right). Source: Cluj Weather Forecast Regional Service Radar Archive (2020), N.M.A. Archive, http://www.wetter3.de/Archiv/, http://www.esrl.noaa.gov, https://www.blitzortung.org/en/archive_data.php
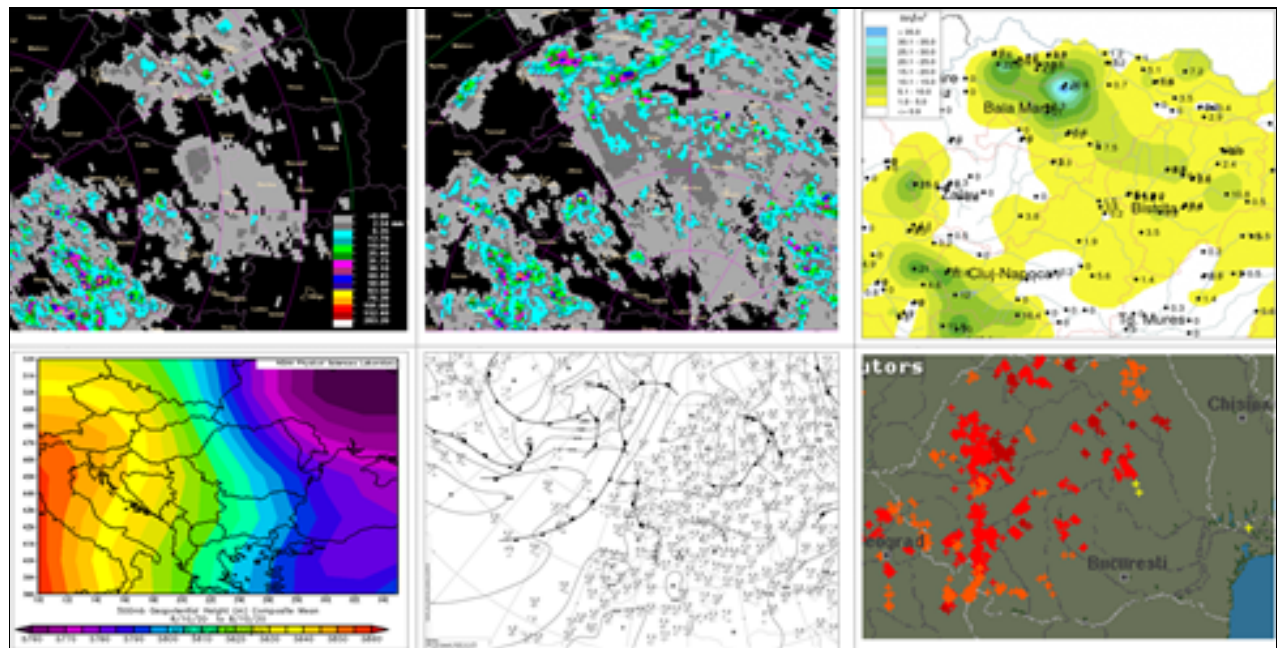

Fig. 7. The USP radar product for RDOD (up-left) and RDBB (up-center), the 24 hrs water amounts recorded at the gauging stations map (up-right), distribution field of the geopotential height at 500 hPa level (gpdam, down-left), sea level pressure and associated frontal systems on the $10^{\text {th }}$ of August, 2020, 12 GMT (down-center), the electrical discharges map (down-right). Source: Cluj Weather Forecast Regional Service Radar Archive (2020), N.M.A. Archive, http://www.wetter3.de/Archiv/, http://www.esrl.noaa.gov, https://www.blitzortung.org/en/archive_data.php 


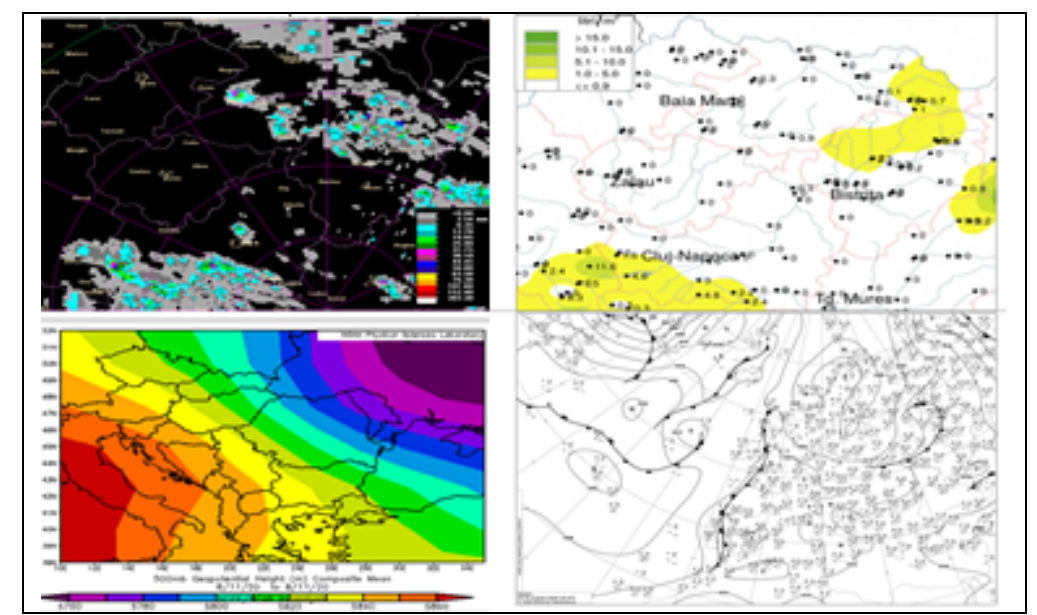

Fig. 8. The USP radar product for RDBB (up-left), the 24 hrs water amounts recorded at the gauging stations map (up-right), distribution field of the geopotential height at 500 hPa level (gpdam, down-left), sea level pressure and associated frontal systems on the $11^{\text {th }}$ of August, 2020, 12 GMT (down-right). Source: Cluj Weather Forecast Regional

Service Radar Archive (2020), N.M.A. Archive, http://www.wetter3.de/Archiv/, http://www.esrl.noaa.gov

On the $11^{\text {th }}$ of August, the precipitations area is diminishing, while the air instability continues within the mountain area. A major difference is obvious in this day, the maximum water amount estimated by RDBB in the mountain zone was $35 \mathrm{~mm}$, compared to the $4.8 \mathrm{~mm}$ quantity, recorded at Băișoara weather station. The RDOD database was unavailable for this period of time due to technical issues. (Fig. 8)

\section{4. $15^{\text {th }}-16^{\text {th }}$ of August, 2020}

For this period, the synoptic analysis highlights the passage of a Mediterranean depression located west of the country, while at the $850 \mathrm{hPa}$ level, the air temperature decreases. On the distribution field of the geopotential height at $500 \mathrm{hPa}$ level map, Romania was on the downward slope of an upper anticyclonic ridge, present above the central-north flank of the European continent (Fig. 9). The air instability increases, starting with Apuseni Mountains and gradually evolving to the eastern side of the studied region. In this conditions, on the $15^{\text {th }}$ of August, 2020, the maximum water amount recorded at Recea Cristur gauging station (Cluj County) was $95.4 \mathrm{~mm}$. For this rainfall amount, RDBB detects in the area a pixel between 63.5 to $76.2 \mathrm{~mm}$ (Fig.9). Overall, for the Cluj-Napoca weather station, RDBB estimated small quantities $(<5 \mathrm{~mm})$, compared to the recorded amount $(25.3 \mathrm{~mm} / 24$ hrs). In this case, RDBB underestimated the water amounts.

On the $16^{\text {th }}$ of August, 2020, the air instability increases for the entire region, and the precipitation area expands (Fig. 10). Again, RDBB underestimated the quantitative rainfall. However, it detects the areas with intense rainfalls, with a mean difference of 15 to $20 \mathrm{~mm}$ (for instance, at Huedin weather station the recorded amount was $40.8 \mathrm{~mm}$, compared with the radar estimation, between 20 to $25 \mathrm{~mm}$, and Recea Cristur gauging station, with more $95 \mathrm{~mm}$, value that was estimated between 63 to $75 \mathrm{~mm}$ ). 


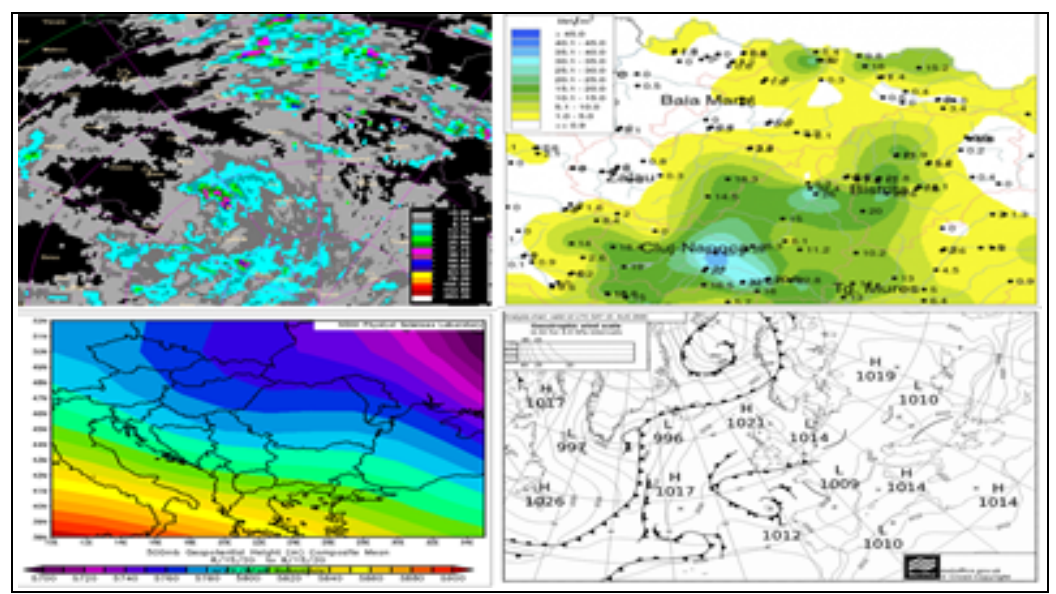

Fig. 9. The USP radar product for RDBB (up-left), the 24 hrs water amounts recorded at the gauging stations map (up-right), distribution field of the geopotential height at 500 hPa level (gpdam, down-left), sea level pressure and associated frontal systems on the $15^{\text {th }}$ of August, 2020, 12 GMT (down-right). Source: Cluj Weather Forecast Regional

Service Radar Archive (2020), N.M.A. Archive, http://www.wetter3.de/Archiv/, http://www.esrl.noaa.gov
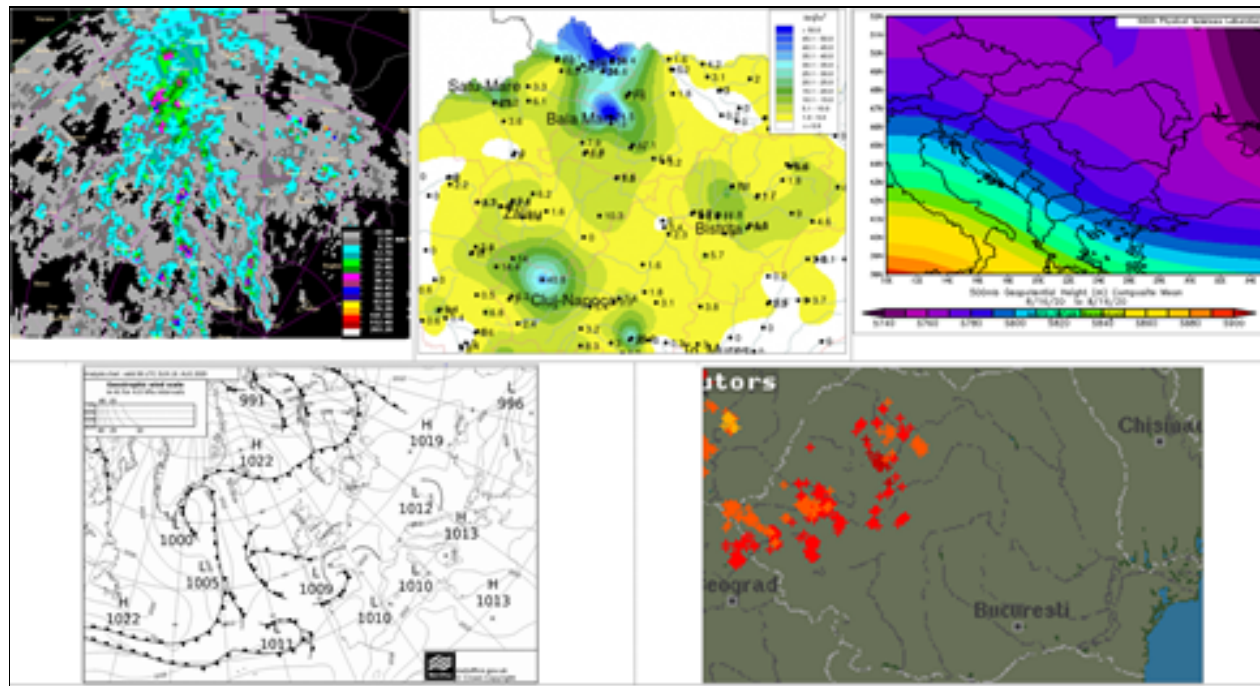

Fig. 10. The USP radar product for RDBB (up-left), the 24 hrs water amounts recorded at the gauging stations map (up-center), distribution field of the geopotential height at $500 \mathrm{hPa}$ level (gpdam, up-right), sea level pressure and associated frontal systems on the $16^{\text {th }}$ of August, 2020, 06 GMT (down-left), the electrical discharges map (down-right).

Source: Cluj Weather Forecast Regional Service Radar Archive (2020), N.M.A. Archive, http://www.wetter3.de/Archiv/, http://www.esrl.noaa.gov, https://www.blitzortung.org/en/archive_data.php 


\section{5. $17^{\text {th }}-19^{\text {th }}$ of August, 2020}

This period is characterized by an intense cyclonic activity, in north-northwestern part of the country. In the first two days of the interval, a pre-frontal synoptic condition is present, the analysed area is on the ascending slope of an upper trough, as we can notice on the $24 \mathrm{hrs}$ precipitations map. On the $17^{\text {th }}$ of August, the convection starts in the Apuseni Mountains, in the afternoon and in the evening, moving eastward, , without electrical discharges (Fig. 11). On the $18^{\text {th }}$ of August, the convective activity increases, starting at noon, as it can be noticed on the electrical discharges map (Fig. 12). Again, the precipitations fields are estimated with a higher accuracy by the RDBB radar, with insignificant differences regarding to the maximum water amounts recorded, especially for Satu Mare and Maramureș counties (situated between 120-200 km distance).

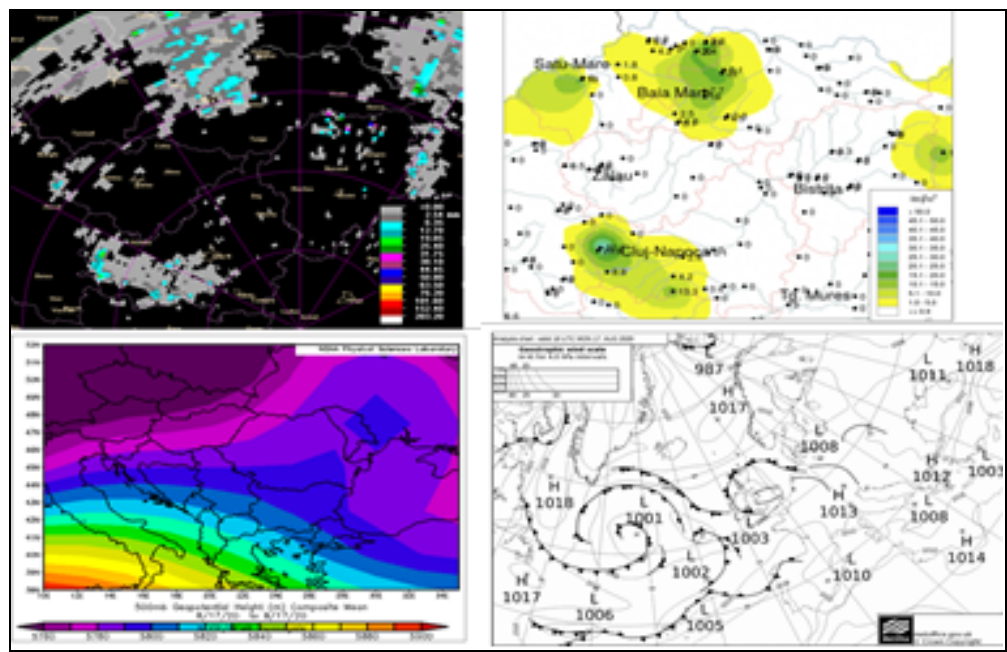

Fig. 11. The USP radar product for RDBB (up-left), the 24 hrs water amounts recorded at the gauging stations map (up-right), distribution field of the geopotential height at $500 \mathrm{hPa}$ level (gpdam, down-left), sea level pressure and associated frontal systems on the $17^{\text {th }}$ of August, 2020, 12 GMT (down-right). Source: Cluj Weather Forecast Regional Service Radar Archive (2020), N.M.A. Archive, http://www.wetter3.de/Archiv/, http://www.esrl.noaa.gov

On the 19th of August, starting in the early morning the frontal system is moving across the analysed area. Thus, the maximum air temperatures decrease from $29^{\circ} \mathrm{C}$ in the previous day, to less than $23^{\circ} \mathrm{C}$ (recorded at Sighetu Marmației weather station).

The weather was cold, the electrical discharges were missing and the precipitations were both rain showers and continuous rains. The water amounts recorded at the weather/gauging stations exceeded $20 \mathrm{~mm}$ on extended areas, with a maximum water amount of $64.3 \mathrm{~mm}$ (Satu Mare weather station), followed by 45.0 $\mathrm{mm}$ at Cavnic (Maramureș County), $46.5 \mathrm{~mm}$ la Sălătig gauging station (Sălaj County), $60.5 \mathrm{~mm}$ at Așchileu Mare gauging station (Cluj County) and $30.9 \mathrm{~mm}$ at Chiraleș gauging station (Bistrița-Năsăud County). 


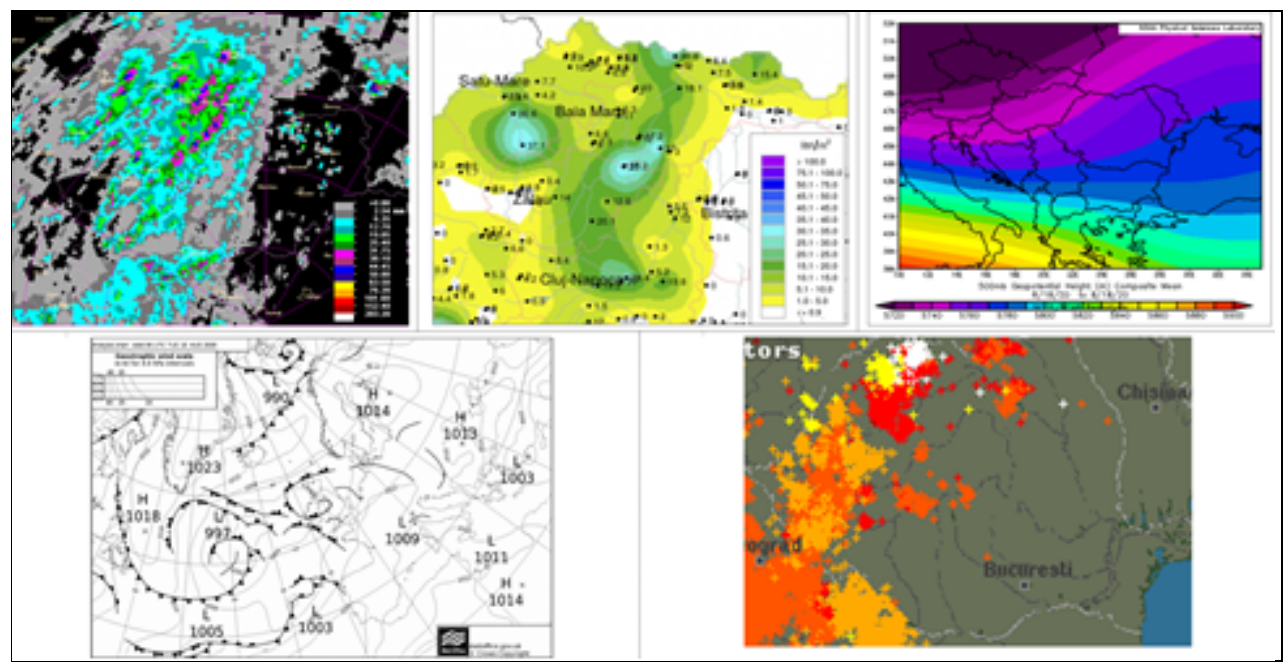

Fig. 12. The USP radar product for RDBB (up-left), the 24 hrs water amounts recorded at the gauging stations map (up-center), distribution field of the geopotential height at $500 \mathrm{hPa}$ level (gpdam, up-right), sea level pressure and associated frontal systems on the $18^{\text {th }}$ of August, 2020, 06 GMT (down-left), the electrical discharges map (down-right).

Source: Cluj Weather Forecast Regional Service Radar Archive (2020), N.M.A. Archive, http://www.wetter3.de/Archiv/, http://www.esrl.noaa.gov, https://www.blitzortung.org/en/archive_data.php

In this synoptic condition, the significant water amounts areas were not estimated by the RDBB. The mean differences exceeded 10 to $15 \mathrm{~mm} / 24 \mathrm{hrs}$. For instance, on the central-west flank of the Sălaj and Satu Mare counties, where 20-25 mm mean water amounts have been recorded, the RDBB estimates only 6.5-12.5 mm. Even though the maximum rainfall amounts are estimated, the differences remain obvious. Thus, Satu Mare County, with a peak of $60.0 \mathrm{~mm}$, was estimated at $25 \mathrm{~mm}$ (Fig. 13). This area is between 150-200 km distance. Located at a smaller distance (50-100 km), the Bistrița-Năsăud precipitations field was better estimated (30.9 mm recorded at the Chirales gauging station, compared to the 25 to $38 \mathrm{~mm}$ estimated by RDBB).

\section{6. $23^{\text {rd }}-25^{\text {th }}$ of August, 2020}

In this period, at ground level, a south-western air circulation caused by a low pressure system situated on the north-north-west side of Romania was present. During afternoon, the convective activity was intensified. The cloud formations are moving SW-NE during the entire period. On the distribution field of the geopotential height at $500 \mathrm{hPa}$ level, a difluence of the baric field is highlighted, which leads to the intense convective activity and associated electrical discharges, especially in the central-eastern and southern part of Romania (Fig. 14).

On the $23^{\text {rd }}$ of August, the water amount recorded at Luna de Jos gauging station (18.0 mm), was identically estimated by both RDOD and RDBB radars. In the opposite, on the $24^{\text {th }}$ of August, both radars estimated the precipitations area, with a 
maximum of 45-65 $\mathrm{mm}$ in $24 \mathrm{hrs}$, at the borderland between Cluj and Alba counties (Fig. 15), while the maximum water amount registered was $50.6 \mathrm{~mm}$ in $24 \mathrm{hrs}$.

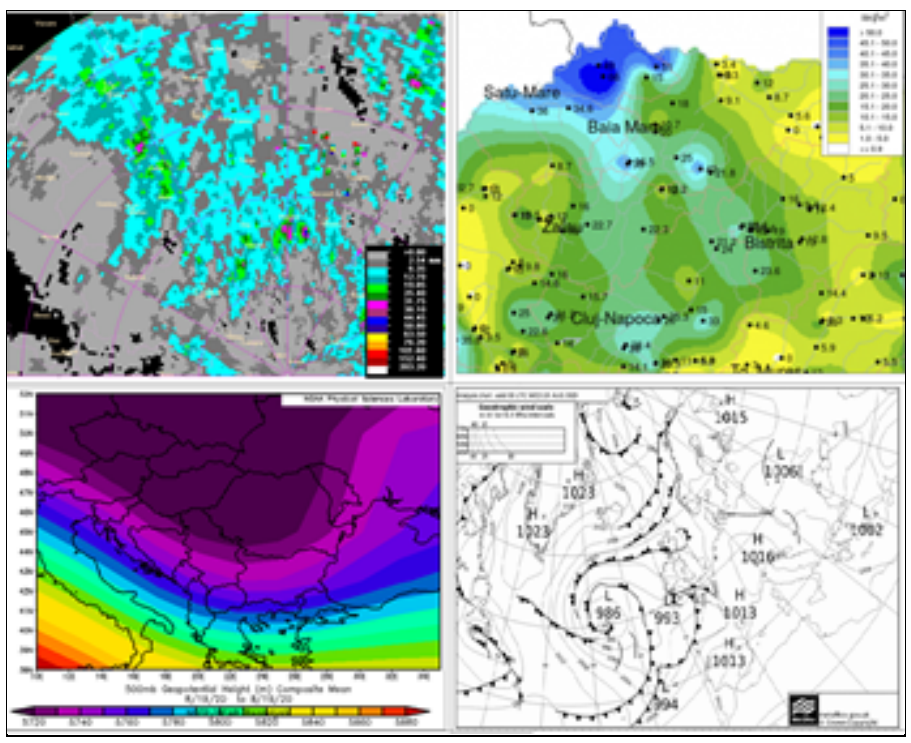

Fig. 13. The USP radar product for RDBB (up-left), the 24 hrs water amounts recorded at the gauging stations map (up-right), distribution field of the geopotential height at $500 \mathrm{hPa}$ level (gpdam, down-left), sea level pressure and associated frontal systems on the $19^{\text {th }}$ of August, 2020, 12 GMT (down-right). Source: Cluj Weather Forecast Regional Service Radar Archive (2020), N.M.A. Archive, http://www.wetter3.de/Archiv/, http://www.esrl.noaa.gov

On the $25^{\text {th }}$ of August, the precipitations field has diminished, leaving only in the mountain area, relative to the radar's estimations (Fig.16). Thereby, RDBB estimated small water amounts, spread on extended areas, approaching the water amount recorded at the gauging stations, while RDOD estimated a small area, with quantities less than $5 \mathrm{~mm}$ in $24 \mathrm{hrs}$, in general. Consequently, the gap between the RDOD and RDBB radars water estimations is highlighted, especially for the eastern part of the area, Cluj and Sălaj counties being the best estimated regions.

\section{RESULTS AND CONCLUSIONS}

Following the analysis of the 14 rainy days from August, 2020, the synoptic conditions were grouped in 6 periods: 4-5, 7-8, 9-11, 15-16, 17-19, 23-25 (Table 1)

Tabel 1. The rainy days classification according to the synoptic conditions

\begin{tabular}{|c|c|c|}
\hline Period & Convective Situations & Frontal Situations \\
\hline $\mathbf{4}^{\text {th }} \mathbf{- 5}^{\text {th }}$ of August & $X$ & - \\
\hline $\mathbf{7}^{\text {th }}-\mathbf{8}^{\text {th }}$ of August & $X$ & - \\
\hline $\mathbf{9}^{\text {th }} \mathbf{1 1}$ of August & $X$ & - \\
\hline $\mathbf{1 5}^{\text {th }}-\mathbf{1 6}^{\text {th }}$ of August & $X$ & $X$ \\
\hline $\mathbf{1 7}^{\text {th }}-\mathbf{1 9}^{\text {th }}$ of August & $X$ & $X$ \\
\hline $\mathbf{2 3}^{\text {rd }}-\mathbf{2 5}^{\text {th }}$ of August & $X$ & $X$ \\
\hline
\end{tabular}



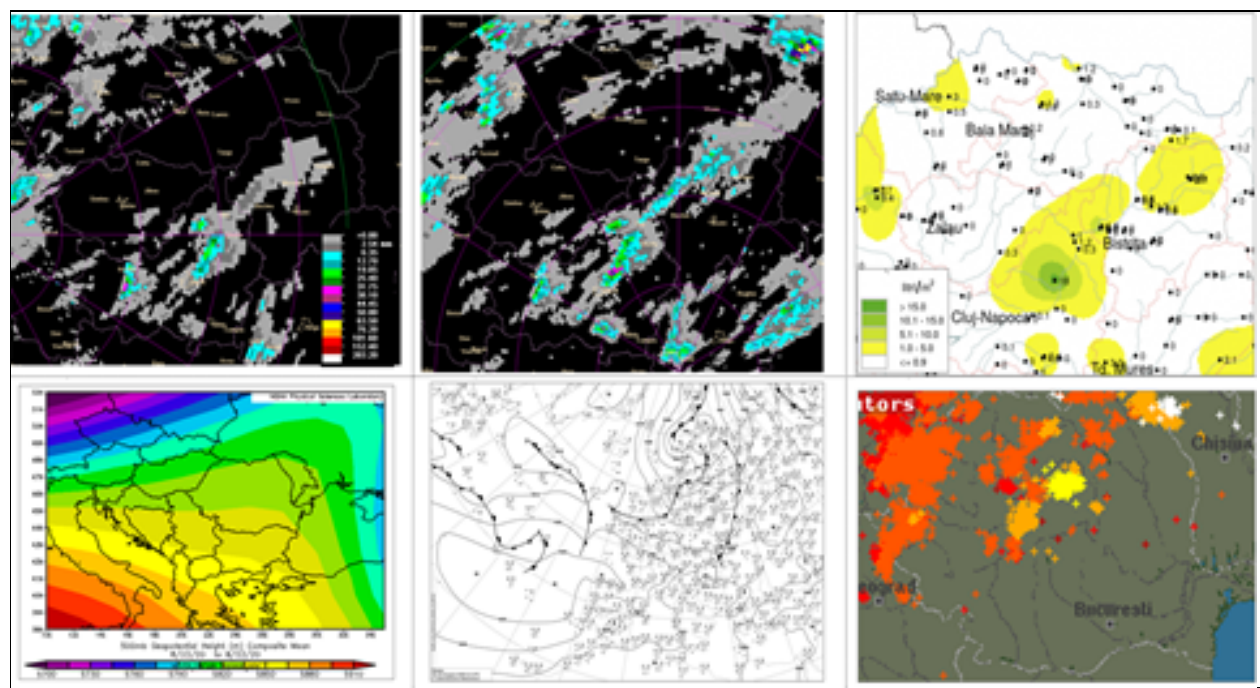

Fig. 14. The USP radar product for RDOD (up-left) and RDBB (up-center), the 24 hrs water amounts recorded at the gauging stations map (up-right), distribution field of the geopotential height at 500 hPa level (gpdam, down-left), sea level pressure and associated frontal systems on the $23^{\text {th }}$ of August, 2020, 12 GMT (down-center), the electrical discharges map (down-right). Source: Cluj Weather Forecast Regional Service Radar Archive (2020), N.M.A. Archive, http://www.wetter3.de/Archiv/, http://www.esrl.noaa.gov, https://www.blitzortung.org/en/archive_data.php
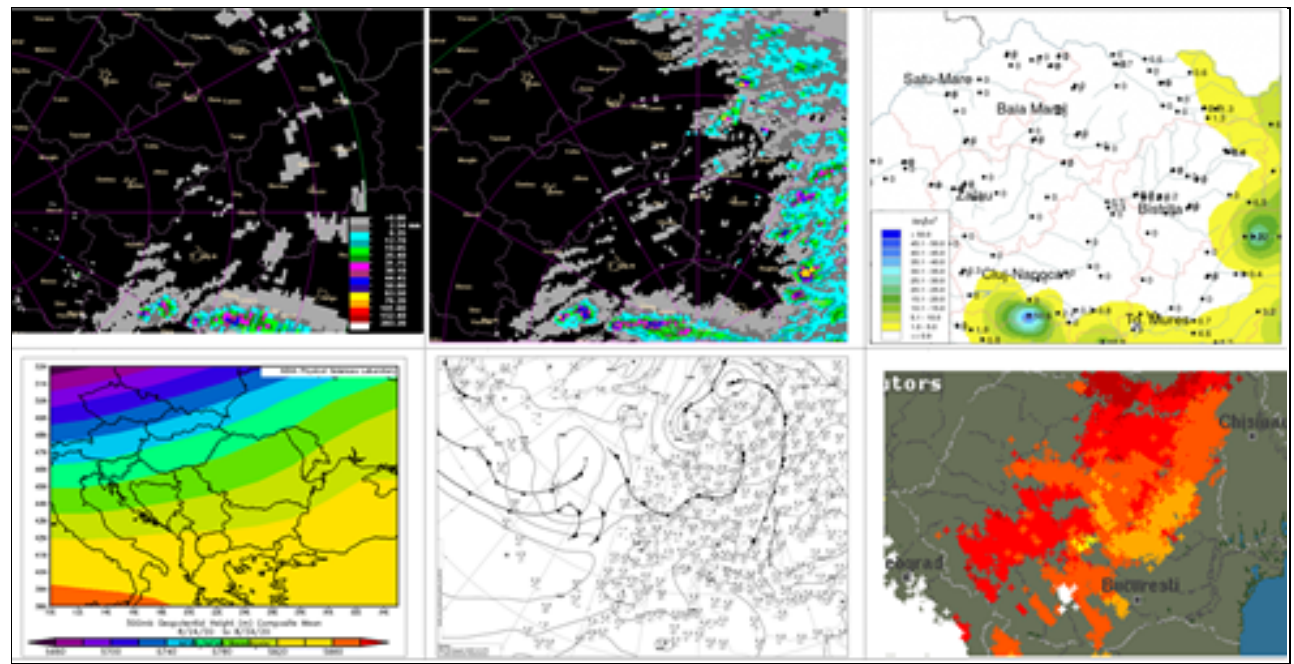

Fig. 15. The USP radar product for RDOD (up-left) and RDBB (up-center), the 24 hrs water amounts recorded at the gauging stations map (up-right), distribution field of the geopotential height at 500 hPa level (gpdam, down-left), sea level pressure and associated

frontal systems on the $24^{\text {th }}$ of August, 2020, 12 GMT (down-center), the electrical discharges map (down-right). Source: Cluj Weather Forecast Regional Service Radar Archive (2020), N.M.A. Archive, http://www.wetter3.de/Archiv/, http://www.esrl.noaa.gov, https://www.blitzortung.org/en/archive_data.php 

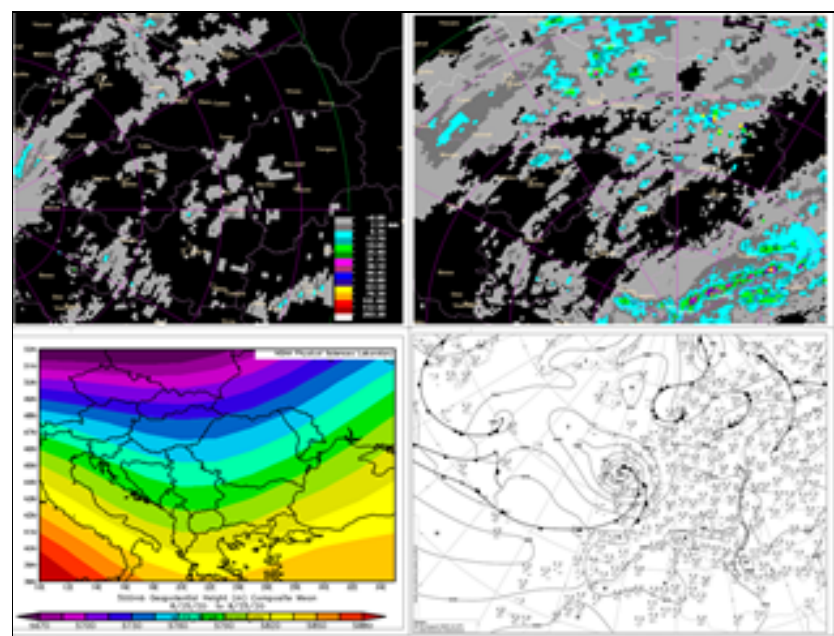

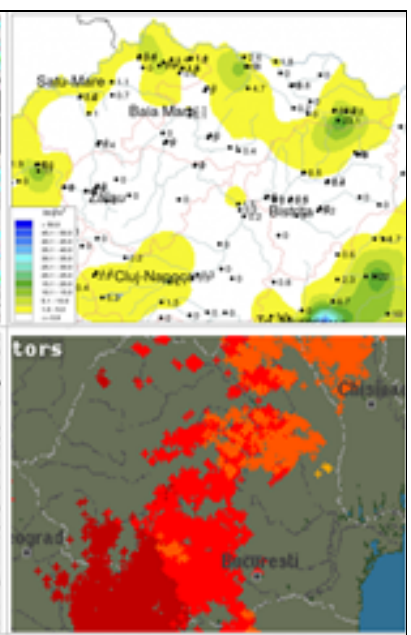

Fig. 16. The USP radar product for RDOD (up-left) and RDBB (up-center), the 24 hrs water amounts recorded at the gauging stations map (up-right), distribution field of the geopotential height at 500 hPa level (gpdam, down-left), sea level pressure and associated frontal systems on the $25^{\text {th }}$ of August, 2020, 12 GMT (down-center), the electrical discharges map (down-right). Source: Cluj Weather Forecast Regional Service Radar Archive (2020), N.M.A. Archive, http://www.wetter3.de/Archiv/, http://www.esrl.noaa.gov, https://www.blitzortung.org/en/archive data.php

The convective and pre-frontal synoptic conditions highlighted that both RDOD and RDBB are in correlation with the registered water amounts, but with abnormalities between different areas. Thus, of the six consecutive periods, the comparison between RDOD and RDBB was made for four of them $\left(4^{\text {th }}-5^{\text {th }}, 7^{\text {th }}-8^{\text {th }}\right.$, $\left.9^{\text {th }}-11^{\text {th }}, 23^{\text {rd }}-25^{\text {th }}\right)$. This cases showed that both radars give a good estimation for the Apuseni Mountains and western flank of Cluj and Sălaj counties, areas located between 50 to $150 \mathrm{~km}$ distance.

For the other areas, RDOD underestimate the water amounts, and also the lack of them for the eastern part of the studied region (Maramureș and Bistrița-Năsăud counties, located between 150 to $200 \mathrm{~km}$ distance). In opposite, RDBB`s estimations are satisfactory for the whole region, including areas located between 150 to $200 \mathrm{~km}$ (Maramureș Country and the north-eastern part of Satu Mare).

On the $4^{\text {th }}$ to $11^{\text {th }}$ and $23^{\text {rd }}$ of August cases, the air instability was determined also by the daily maximum temperatures regime, greater than $30^{\circ} \mathrm{C}$, which generated convective instability during afternoon and evening.

The other periods (15-16, 17-19, 23-25) highlights both pre-frontal convective situation at the beginning, and the frontal systems at the end of the period. In this 
cases, during pre-frontal situations, the RDBB estimations are in a good correlation with the water amounts measured at the weather/gauging stations.

On the other hand, during the frontal situations, that occurred early in the morning (16 $6^{\text {th }}$ and $19^{\text {th }}$ of August) and lasting for the whole day, generating rain showers and heavy rains, accumulating significant amounts of water. In this conditions, RDBB underestimated the water amounts, with quantities between 20 to $25 \mathrm{~mm}$ in $24 \mathrm{hrs}$.

On the $24^{\text {th }}$ to $25^{\text {th }}$ of August period, the frontal systems manifested during afternoon and evening, with frequently rain showers and associated electrical discharges. In this situations, the estimations of RDOD and RDBB were close to the water amount measured within gauging stations, for the Apuseni Mountains and Cluj and Sălaj counties western flank. For the eastern half and the northern part of the region, the estimations were unsatisfactory for RDOD, while RDBB had a suitable estimation.

After this study, it was highlighted the fact that during convective and pre-frontal situations, both RDOD and RDBB detects the precipitations areas and the maximum water amounts registered, emphasizing at the same time that RDOD has a good estimation of the water amount registered for the Apuseni Mountains and Cluj and Sălaj counties western flank, while RDBB detects the quantitative rainfall amounts for the whole area.

Finally, during frontal situations, in which frontal systems occur early in the morning, the weather radar presents difficulties in estimating the rainfall amounts, even though the Bobohalma radar detects the significant rainfall amounts areas, but underestimated comparative to the measured quantities.

\section{REFERENCES}

1. Burcea S., Cheval S., Dumitrescu A., Antonescu B., Bell A., Breza T. (2012)

2. Comparison between radar estimated and rain gauge measured precipitation in the Moldavian Plateau - April 2012 Environmental Engineering and Management Journal 11(4):723-731 DOI: 10.30638/eemj.2012.092, accesed 30.10.2020;

3. Espinosa B., Hromadka T.V., Perez R. (2015) Comparison of radar data versus

4. rainfall data; https://core.ac.uk/display/91706987 accesed 30.10.2020;

5. Kreklow J., Tetzlaff B., Burkhard B., Kuhnt G. (2020) Radar-Based

6. Precipitation Climatology in Germany-Developments, Uncertainties and Potentials Atmosphere 2020, 11(2), 217; https://www.mdpi.com/20734433/11/2/217, accesed 30.10.2020;

7. *** Northern Transylvania Regional Meteorological Center - Weather Forecast

8. Regional Service - USP (User Selectable Precipitation - $24 \mathrm{hrs)} \mathrm{Radar}$ 
9. Archive, accesed 30.09.2020;

10. *** National Meteorological Administration - Archive of the $24 \mathrm{hrs}$

11. precipitations maps, accesed 30.09.2020;

12. *** (2020), http://www.esrl.noaa.gov, accesed 30.09.2020;

13. *** http://www.wetter3.de/Archiv/, accesed 30.09.2020;

14. $* * * \mathrm{https}: / / \mathrm{www}$. blitzortung.org/en/archive_data.php, accesed 30.09.2020. 